\title{
Mortality of nickel workers: experience of men working with metallic nickel
}

\author{
J E COX, ${ }^{1}$ R DOLL, ${ }^{2}$ W A SCOTT, ${ }^{2}$ AND S SMITH ${ }^{1}$ \\ From Henry Wiggin and Co Ltd, ${ }^{1}$ Hereford, and Imperial Cancer Research Fund, ${ }^{2}$ Cancer Epidemiology \\ and Clinical Trials Unit, University of Oxford, Oxford, UK
}

\begin{abstract}
The mortality of men employed in a plant manufacturing nickel alloys from metallic nickel and other metals has been examined. The plant has operated since May 1953, and 1925 men were identified who had been employed in the operating areas at the plant, other than as members of the staff, for a total of five or more years, excluding breaks. Analysis of samples of air obtained from personal samplers showed that since 1975 most of the men are likely to have been exposed to average concentrations of nickel of between 0.5 and $0.9 \mathrm{mg} \mathrm{Ni} / \mathrm{m}^{3}$. All but $22(1.1 \%)$ of the men were successfully traced to 1 April 1978 or until they died or emigrated. One hundred and seventeen had died. The numbers of deaths observed from cancers of respiratory and other sites, other respiratory disease, ischaemic heart disease, and other causes of death were compared with the numbers expected from national and local mortality rates. No evidence of the existence of any occupational hazard was obtained. The number of deaths from lung cancer (15) in men employed for five years or more is small. At $98 \%$ of the number expected at local rates it is statistically compatible with risks of between 0.5 and $2 \cdot 2$ times "normal."
\end{abstract}

Work in nickel refineries in Canada, Norway, the USSR, and Wales has long been known to be associated with an increased risk of developing bronchial or nasal sinus cancer (see Sunderman ${ }^{1}$ for review). The risk was at one time substantial; but despite this, it has not yet been possible to define precisely the conditions under which it occurred. Metallic nickel is carcinogenic in laboratory experiments in which it is injected into the muscles, pleura, or marrow of rats, ${ }^{2}$ but it does not necessarily follow that pure nickel is the responsible agent in man. The occupational cancers that have been observed were associated particularly with high temperature oxidation of nickel ore in some obsolete processes of calcining and sintering, and it is possible that the risk was characteristic of exposure to nickel subsulphide, which is the compound of nickel that most readily produces bronchial carcinoma in inhalation experiments on rats. ${ }^{3}$ Alternatively, it may have been due to a mixture of sulphides, oxides, and metallic nickel which are individually less active in laboratory experiments. ${ }^{2}$ We have, therefore, examined the mortality experience of men employed at Henry

Received 27 August 1980

Accepted 10 September 1980
Wiggin's works in Hereford, many of whom have been regularly exposed to fumes and dust from metallic nickel and nickel oxide but have not been exposed to subsulphide.

\section{The factory}

The plant manufactures nickel alloys from raw materials consisting of metallic nickel and other metals-for example, iron, copper, cobalt, chrome, and molybdenum. It is situated on the outskirts of Hereford, a small non-industrialised town with a static population of 50000 in one of the most rural parts of England. The plant was constructed between 1951 and 1953, and the first production melt took place in May 1953.

Melting facilities include induction, direct arc and vacuum furnaces, and two units for electro-flux refining. Primary hot working processes are extrusion and forging centred round a 5000-tonne extrusion press and a 1500-tonne forging press. Secondary hot working takes place in the hot strip and rod mill and hot sheet rolling mill. Cold working processes include tube reducing, tube and bar drawing, sheet and strip rolling, and rod and wire drawing. Other production operations include coin-blanking and 
powder atomisation and hot isostatic pressing. Subsidiary processes include pickling, grinding, and annealing. Finally, there are service functions such as engineering, inspection, stores, and distribution.

Measurements of dust in the factory air have been made systematically since 1975 . In an attempt to provide realistic measure of the amounts actually inspired, samples have been taken by Casella samplers pinned to the coat lapels of men at work over periods of two, four, or eight hours. Flow rates have been adjusted to between 1 and 2 litres a minute, and rates have been measured at the beginning, middle, and end of each period to ensure even functioning. The average results obtained over the past five years in 18 operating areas grouped hierarchically into five categories according to the concentrations of dust and nickel in the air are shown in tables 1 and 2 . Individual observations, however, varied greatly from time to time. Measurements in areas in category 1 , for example, varied from $0 \cdot 1$ to $17 \cdot 5^{*} \mathrm{mg} \mathrm{Ni} / \mathrm{m}^{3}$ and from 0.4 to $2.9 \mathrm{mg} \mathrm{Ni} / \mathrm{m}^{3}$ when the $5 \%$ most extreme measurements at each end of the range were

*A measurement made in the first months after the installation of new powder atomisation equipment which led to rapid remedial action.

Table 1 Categorisation of operating areas

\begin{tabular}{ll}
\hline Category & Operating area \\
\hline 1 & Melting \\
& Fettling \\
& Pickling \\
& Extrusion and forge \\
Hot strip and rolling & Engineering \\
Melting stores \\
Machining \\
Hot rolling \\
Nimonic finishing \\
Craft apprentice \\
Roll turning and grinding \\
Cold rolling \\
Cold drawing \\
Wire drawing \\
& Inspection \\
& Process stock handling \\
5 & Distribution and warehouse \\
\hline
\end{tabular}

excluded. Before 1975 samples were taken only when problems arose or to monitor the effect of control measures. Measurements were made only by static samplers, sited close to the source of dust, and the results cannot be regarded as typical of the extent to which individuals were exposed. Results ranged from 10.2 to $35.1 \mathrm{mg}$ of total dust and 1.8 to $17.0 \mathrm{mg}$ $\mathrm{Ni} / \mathrm{m}^{3}$ with median observations of $12.0 \mathrm{mg}$ of total dust and $2.5 \mathrm{mg} \mathrm{Ni} / \mathrm{m}^{3}$.

Forty-six analyses of the state in which the nickel was found in the air of different parts of the factory (melting and fettling departments and welding and extrusion sections) showed gross variations from one part of the factory to another: from $14 \%$ metallic in the welding section to $50 \%$ in the fettling department, from $10 \%$ refractory in the fettling department to $70 \%$ in the melting department, and from $14 \%$ water soluble in the melting department to $47 \%$ and $49 \%$ respectively in the welding and extrusion sections.

\section{The employees}

Most of the workers recruited in the first few years transferred from similar factories in Birmingham (679 men) and Glasgow (129 men). Subsequently men were recruited locally, mostly from nonindustrial backgrounds. The payroll increased rapidly from 169 in 1953 to a peak of 3632 in 1965 and has remained fairly constant between 2300 and 2800 in the past 12 years (1967-78). Turnover was rapid in the first year of employment, but slow subsequently. In the past ten years the average length of service has been of the order of 10-11 years.

A medical department existed from the beginning and carried out pre-employment examinations. Production work required a high standard of efficiency, and only completely fit men were accepted for work in the production areas.

\section{Method}

Exposure to a weak carcinogen or to a weak concentration of a strong carcinogen is unlikely to

Table 2 Measurement of pollution of workshop air by category of operating area: average values 1975-80

\begin{tabular}{|c|c|c|c|c|c|c|c|}
\hline \multirow[t]{2}{*}{ Category of area* } & \multirow{2}{*}{$\begin{array}{l}\text { No of samples } \\
\text { examined }\end{array}$} & \multicolumn{6}{|c|}{ Concentration in $\mathrm{mg} / \mathrm{m}^{3}$} \\
\hline & & Total dust & Nickel & Iron & Cobalt & Copper & Chromium \\
\hline $\begin{array}{l}1 \\
2 \\
3 \\
4 \\
5\end{array}$ & $\begin{array}{r}624 \\
503 \\
124 \\
180 \\
17\end{array}$ & $\begin{array}{l}9 \cdot 57 \\
4 \cdot 49 \\
3 \cdot 29 \\
1 \cdot 01 \\
1 \cdot 05\end{array}$ & $\begin{array}{l}0.84 \\
0.53 \\
0.55 \\
0.40 \\
0.04\end{array}$ & $\begin{array}{r}0.83 \\
0.45 \\
0.20 \\
0.11 \\
<0.01\end{array}$ & $\begin{array}{l}0.51 \\
0.49 \\
0.45 \\
0.05 \\
0.00\end{array}$ & $\begin{array}{r}0.24 \\
0.22 \\
0.10 \\
0.05 \\
<0.01\end{array}$ & $\begin{array}{r}0.19 \\
0.15 \\
0.13 \\
0.06 \\
<0.01\end{array}$ \\
\hline
\end{tabular}

*See table 1 . 
produce a detectable increase in the incidence of cancer in a small group of men unless it is continued for many years. We therefore limited our main study to men who had been employed in the operating area at the plant, other than as members of the staff, for a total of five or more years, excluding breaks. The company's payroll and medical records were searched, and a total of 1925 men were found to have satisfied this criterion before 1 April 1978. For each of these men a record was made of his date of birth, dates of first and subsequent employments, dates of leaving employment (if not still employed at the end of the follow-up period), previous employment by the company at other nickel works, occupation on first employment, and all subsequent changes of occupation with the dates of each change. Occupations were grouped according to the place of work in the 18 operating areas listed in tables 1 and 2. A sixth category was subsequently added to include men who were transferred to the staff from other occupations.

An attempt was made to follow each man until 1 April 1978 or until he emigrated from Britain or died. Information about the status of men who had ceased employment and were not receiving a company pension was sought from the records of the National Health Service Register at Southport. Table 3 shows the results of the follow-up.

Table 3 Status of men in study at completion of follow-up

\begin{tabular}{lrc}
\hline Status & No of men $(\%)$ \\
\hline Alive & & \\
$\quad$ Still employed & 1054 & $(54 \cdot 8)$ \\
Left employment & 710 & $(36 \cdot 9)$ \\
Emigrated & 22 & $(1 \cdot 1)$ \\
Dead & 117 & $(6 \cdot 1)$ \\
Untraced & 22 & $(1 \cdot 1)$ \\
All statuses & $1925(100 \cdot 0)$ \\
\hline
\end{tabular}

Causes of death for the 117 men found to have died were assigned to the underlying cause recorded on the death certificate and coded according to the 8th revision of the international list of causes of death. ${ }^{4}$ The number of observed deaths was then compared with the number that would have been expected if the men had experienced the same rate of mortality as the male residents of Herefordshire towns. For this purpose, men who were untraced at 1 April 1978 were excluded from the population from the time they were last known to have been alive (usually the date of ceasing employment) and men who had emigrated from the date of emigration. The number of man-years at risk of death were calculated separately for each five-year age group in each of the calendar periods 1958-60,1961-65, 1966-70, and 1971-78. The number of deaths that would have been expected from different groups of causes if the men had experienced the same mortality rates as those recorded in all England and Wales were calculated by multiplying the numbers of man-years at risk in each five-year age group by the corresponding national rates for the periods* 1956-60, 1961-65, 1966-70, and 1971-75 after adjusting for the change from the 7 th to the 8th revision of the international list. The numbers obtained were then corrected for geographical location by multiplying by the standardised mortality ratios for the urban areas of the county in which the factory was located. For this purpose, we used the mortality ratios for men aged 15-64 years for the period 1969-73, which may be obtained on request from OPCS. These ratios were preferred to the ratios for all ages, mainly because $97 \%$ of the years under observation related to men aged under 65 , but partly because the inclusion of an open-ended age group ( 75 years of age and older) in the calculation of the ratio for all ages casts doubts on their

*Available from the publications of the Institute of Cancer Research and the Office of Population Censuses and Surveys.

Table 4 Numbers of deaths observed and expected by cause

\begin{tabular}{|c|c|c|c|c|}
\hline \multirow[t]{2}{*}{ Cause of death } & \multicolumn{2}{|c|}{ No of deaths } & \multirow{2}{*}{$\begin{array}{l}\text { SMR } \\
\text { Herefordshire urban areas }\end{array}$} & \multirow{2}{*}{$\begin{array}{l}\text { Observed deaths as } \\
\text { percentage of deaths } \\
\text { expected in locality (ie No } \\
\text { expected at national rates } \\
\text { multiplied by local } \\
\text { SMR/100) }\end{array}$} \\
\hline & Observed & Expected at national rates & & \\
\hline \multicolumn{5}{|l|}{ Cancer } \\
\hline Lung & 15 & $18 \cdot 21$ & $87\}$ & 98 \\
\hline $\begin{array}{l}\text { Other respiratory sites } \\
\text { Other sites }\end{array}$ & 1 & $\begin{array}{r}0.51 \\
24.01\end{array}$ & $\left.-\frac{1}{89}\right\}$ & 85 \\
\hline Other respiratory disease & $5 *$ & $\begin{array}{l}24 \cdot 01 \\
15 \cdot 53\end{array}$ & $\begin{array}{l}89 \\
84\end{array}$ & $\begin{array}{l}85 \\
38\end{array}$ \\
\hline Ischaemic heart disease & 41 & $53 \cdot 13$ & 78 & $\begin{array}{l}30 \\
99\end{array}$ \\
\hline Other cause & 37 & $47 \cdot 12$ & 111 & 71 \\
\hline All causes & $117^{*}$ & $158 \cdot 51$ & 91 & 81 \\
\hline
\end{tabular}

$\mathrm{SMR}=$ Standardised mortality ratio for men aged 15 to 64 years in Herefordshire urban areas, 1969-73; assumed to be 100 for cancer of "other respiratory sites."

*In comparison with the number expected in locality, $\mathrm{p}$ (other respiratory disease) $=0.009$, and (all causes) $=0.02$. 
validity. No correction was made for the expected numbers of cancers of the respiratory system other than lung cancer, because the confidence limits of the mortality ratios were too wide.

To supplement the main investigation, the medical records were searched and inquiries were made locally about the occurrence of nasal sinus cancer in any of the employees of the plant who did not qualify for inclusion in the main study.

\section{Results}

The numbers of deaths observed and expected from all causes and from six cause-groups are shown in table 4. In no group was the observed mortality more than expected. The overall mortality was $81 \%$ of that expected at local rates and varied by cause from $38 \%$ for respiratory diseases other than cancer to $99 \%$ for ischaemic heart disease. Sixteen deaths were attributed to cancers of the respiratory system $(98 \%$ of the number expected); 15 of them were attributed to cancer of the lung and one to cancer of the larynx. No deaths were attributed to cancer of the nasal sinuses. The deficiency of deaths from all causes and from non-malignant respiratory disease, in comparison with the numbers expected in the locality, was, in each case, statistically significant ( $p=0.02$ and $\mathrm{p}<0.01$ ).

With only 117 deaths in total and a low mortality rate from all causes it is unlikely that a significantly high mortality could have been recorded from any major cause of death among any occupational subgroup. We have, however, examined separately the mortality rates for: (a) men who were likely to have had more than average exposure to atmospheric nickel, (b) men who had not previously been employed in one of the company's other nickel works before being employed at Hereford, and (c) men who were under observation five or more years after entering the study - that is, at least 10 years after first employment at Hereford-when any occupational hazard of cancer would be most likely to be seen. In each case we have compared the numbers of observed deaths with the numbers expected at the mortality rates characteristic of men living in Herefordshire towns. For these purposes, we defined men as likely to have had more than average exposure to atmospheric nickel if they were employed in an occupation classified in categories 1 or 2 at any time during the initial five years' employment required to qualify them for entry into the study. Records of employment showed that such men were engaged in occupations classified in the same categories for $85 \%$ of the time they were employed in the plant during the period of observation.

The results are shown in table 5. The ratio of the numbers of deaths observed and expected from lung cancer is marginally greater for men with the greatest exposure to atmospheric nickel and for men who have been observed for at least 10 years after first employment at Hereford; but it is marginally less for men who had not been employed at other nickel works before employment in Hereford began. In no case was the excess mortality statistically significant ( $p$ one-sided test, always, $>0 \cdot 1$ ).

The results of the supplementary inquiry about the occurrence of nasal sinus cancer in other men employed in the works but not included in the main study showed that one man might have developed the disease. The affected man was born on 4 January 1915 and had been employed as a stoker both in the Royal Navy for 13 years and with a firm making cider for eight. He joined Henry Wiggin on 27 October 1953 as a boiler house attendant and continued in this occupation until his illness. He never worked in any of the operating areas covered by the main study, where nickel dust might have been encountered. He reported sick on 26 August 1957 and died on 10 January 1958. "Neoplasms of the left nasal chamber" with secondaries in the neck

Table 5 Mortality in selected groups

\begin{tabular}{|c|c|c|c|c|c|c|}
\hline \multirow[t]{2}{*}{ Causes of death } & \multicolumn{2}{|c|}{$\begin{array}{l}\text { Men with above average exposure to } \\
\text { atmospheric nickel }\end{array}$} & \multicolumn{2}{|c|}{$\begin{array}{l}\text { Men not employed at other nickel works } \\
\text { before }\end{array}$} & \multicolumn{2}{|c|}{$\begin{array}{l}\text { Men under observation more than } 5 \text { years } \\
\text { after entry to study }\end{array}$} \\
\hline & $\begin{array}{l}\text { No of deaths } \\
\text { observed }\end{array}$ & $\begin{array}{l}\text { Observed deaths as } \\
\text { percentage of } \\
\text { expected } \dagger\end{array}$ & $\begin{array}{l}\text { No of deaths } \\
\text { observed }\end{array}$ & $\begin{array}{l}\text { Observed deaths as } \\
\text { percentage of } \\
\text { expected } \dagger\end{array}$ & $\begin{array}{l}\text { No of deaths } \\
\text { observed }\end{array}$ & $\begin{array}{l}\text { Observed deaths as } \\
\text { percentage of } \\
\text { expected } \dagger\end{array}$ \\
\hline $\begin{array}{l}\text { Cancer of lung } \\
\text { Other cancer } \\
\text { Ischaemic heart }\end{array}$ & $\begin{array}{l}9 \\
8\end{array}$ & $\begin{array}{r}124 \\
79\end{array}$ & $\begin{array}{l}12 \\
14\end{array}$ & $\begin{array}{l}89 \\
74\end{array}$ & $\begin{array}{l}13 \\
14\end{array}$ & $\begin{array}{r}111 \\
90\end{array}$ \\
\hline $\begin{array}{l}\text { disease } \\
\text { Other cause }\end{array}$ & $\begin{array}{l}24 \\
12 *\end{array}$ & $\begin{array}{r}125 \\
40\end{array}$ & $\begin{array}{l}32 \\
31 \ddagger\end{array}$ & $\begin{array}{l}90 \\
55\end{array}$ & $\begin{array}{l}33 \\
28\end{array}$ & $\begin{array}{r}107 \\
62\end{array}$ \\
\hline All causes & 53 & 79 & 89 & 71 & 88 & 85 \\
\hline
\end{tabular}

$* p<0.001$.

†At National rates corrected for locality.

$\mp \mathbf{p}<0.01$.

§At least 10 years after first employment in Hereford works. 
was diagnosed at the Hereford County Hospital. Biopsy showed a papilloma with "restless" stratified squamous epithelium with numerous mitoses, suspicious of malignancy. He was treated by radiotherapy but rapidly deteriorated. Death was certified as due to carcinoma of the nasopharynx.

\section{Discussion}

Our results provide no indication of the existence of an occupational hazard of cancer or of any other fatal disease in a factory in which men have been regularly exposed to atmospheres containing on average between 0.04 and $0.84 \mathrm{mg} / \mathrm{m}^{3}$ nickel and nickel oxide in the form of fine particles, half by weight being of respirable size (less than $5 \mu$ diameter). The fact that one employee may have developed cancer of the nasal sinus is not evidence of an occupational hazard, as he was not employed in the operating areas and developed the disease less than four years after first employment in the plant. Of all the 80 cases of nasal sinus cancer that have occurred in men employed in the nickel refinery in South Wales, where there had been a high risk of developing the disease, none appeared within 15 years of first employment (L Morgan, personal communication).

The number of deaths observed in men who were exposed for five or more years is, however, small, and a hazard of twice the normal risk of lung cancer in men with more than average exposure could have been missed by chance $(5 \%$ confidence limits of the ratio of the "true" observed to expected numbers of deaths from lung cancer, 0.5 to $2 \cdot 2$ ). Moreover, the plant has been in operation only since 1953, and few men have been followed for more than 20 years from the date of their first employment. It must also be noted that the risk of death from respiratory disease other than cancer was well below the normal risk for the locality in which the men were employed and for the most part lived. It can, therefore, be argued that men susceptible to chronic respiratory disease had been excluded by the pre-employment medical examination or by self-selection within five years because of the rigour of the work. This would not, however, be expected to have had a large effect on the hazard of lung cancer as only about a fifth of cigarette smokers react by developing chronic obstructive lung disease. ${ }^{5}$ Unfortunately it was not possible to obtain an accurate picture of the smoking habits of the employees, as the records of smoking habits were incomplete and the response to a questionnaire sent to current employees was inadequate for scientific analysis.

The fact that the overall mortality was significantly low may be attributed partly to chance and partly to the selection of healthy men for prolonged employment in a heavy industry. Great care was taken to ensure that no men were omitted from the nominal roll and two of us (JEC and SS) accept personal responsibility for its completeness. The small proportion of men not successfully traced $(1 \cdot 1 \%)$, combined with two searches of the National Health Service Register, makes it unlikely that any material number of deaths was missed.

We thank Mr J Kenowright and Mr J E Thompson of Henry Wiggin for extracting the information about individual employees and Mrs T S Cornish and Miss $C$ Lewis for secretarial help.

\section{References}

${ }^{1}$ Sunderman FW Jr. A review of the carcinogenicities of nickel, chromium and arsenic compounds in men and animals. Prev Med 1976;5:279-94.

2 International Agency for Research on Cancer. IARC Monographs on the evaluation of carcinogenic risk of chemicals to man. Vol 11. Lyon: International Agency for Research on Cancer, 1976.

${ }^{3}$ Ottolenghi AD, Haseman JK, Payne WW, Falk HL, Macfarland HN. Inhalation studies of nickel sulfide in pulmonary carcinogenesis of rats. J Nat Cancer Inst 1975;54:1165-72.

${ }^{4}$ World Health Organisation. Manual of the international statistical classification of diseases and causes of death. 8th revision. Geneva: World Health Organisation, 1968.

${ }^{5}$ Fletcher $\mathrm{C}$, Peto R, Tinker C, Speizer FE. The natural history of chronic bronchitis and emphysema. Oxford: Oxford University Press, 1976. 